\title{
Entre a escrita e a edição: “A Descrição da Patagônia” de Thomas Falkner
}

\author{
Between writing and editing: \\ "The description of Patagonia" Thomas Falkner
}

Maria Cristina Bohn Martins*

\section{Resumo:}

Em 1774 em Hereford, Inglaterra, veio a luz a "Descripcion of Patagonia and Adjoinjing Parts of South America", obra cuja autoria é atribuída ao religioso Thomas Falkner, sacerdote da Companhia de Jesus no Rio da Prata até 1767 quando, cumprindo a decisão de expulsão da sua Ordem dos territórios castelhanos ditada por Carlos III, regressou ao seu país natal. Escrito em parte por meio da memória do jesuíta, e sendo resultado de suas atividades como membro de uma Ordem religiosa, o livro dever ser entendido todavia, levando em conta que texto sofreu, antes de ser publicado, um acentuado processo de edição por parte de William Combe que assina o prefácio da obra. Assim sendo, este artigo analisa a referida obra discutindo sobre o seu contexto de produção e edição para, depois, refletir brevemente sobre a circulação e recepção do texto entre os contemporâneos.

Palavras-chave: Descrição da Patagônia; Autoria; Edição; Jesuítas, Rio da Prata

\begin{abstract}
:
In 1774 in Hereford, England, came to light the book "Description of Patagonia and Adjoining Parts of South America", attributed to the religious Thomas Falkner, priest of the Company of Jesus in the region of Rio da Prata until 1767 when, following the decision that expelled his Order from Spanish territories by Carlos III, returned to his home country. Written in part from the jesuit's memory, and being a result of his work as member of a religious Order, the book must be understood, however, taking into account an accentuated editing process by William Combe, editor that signs the work's preface. This way, this article analyzes the referred work discussing the context of its production and editing to, then, briefly reflect about its circulation and reception among contemporaries.
\end{abstract}

\footnotetext{
* Bolsista Produtividade do CNPq. Professora do Programa de Pós Graduação em História da Universidade do Vale do Rio dos Sinos - UNISINOS, RS, Brasil.
} 
Key words: Description of Patagonia; Authorship; Editing; Jesuits; Río de la Plata

Recibido: 20 de abril de 2015

Evaluado: 10 de mayo de 2015 
As obras - mesmo as maiores, ou, sobretudo, as maiores não tem sentido estático, universal, fixo. Elas são investidas de significados plurais e móveis [...]. Os sentidos atribuídos as suas formas e aos seus motivos dependem das competências ou das expectativas dos diferentes públicos que delas se apropriam (Chartier, 1994).

Nos anos centrais da segunda metade do século XVIII, um idoso sacerdote jesuíta chamado Thomas Falner escreveu, na Inglaterra, um manucrito a respeito de certos territórios situados no extremo sul americano, sobre os quais pouco ainda se conhecia na Europa. Falkner cumpria então, a ordem de banimento dos domínios da coroa castelhana no Novo Mundo, imposta à Companhia de Jesus por Carlos III de Espanha. Discorrendo sobre os extensos territórios da Província de Buenos Aires à qual estivera ligado por muitos anos de sua vida, o sacerdote pronunciou um juízo bastante crítico das condições daquela região. Afirma assim, que os moradores da região

[...] no son gran cosa como soldados, y tan descontentos se hallan con el gobierno español, mal estado de los negócios, carestia de todo lo que son mercaderías de ultramar, y lo que es peor, impuestos exorbitantes, etcétera que de buen grado se verían submetidos de cualquier otra nación que los libertara de la opresión en que se hallan sumidos. Y todo esto no obstante, el país entero está sin más defensa que una poca tropa veterana em Buenos Aires y Montevideo; y bastaria tomar estas dos plazas para que todo el país se sometiera con sólo hacer un paseo militar por él, porque los criollos se harían unos con el enemigo cualquiera que fuese ${ }^{1}$.

A passagem destacada faz parte da obra "A description of Patagonia, and the adjoining parts of South America: containing an account of the soil, produce, animals, vales, mountains, rivers, lakes, \&c. of those countries; the religion, government, policy, customs, dress, arms, and language of the Indian inhabitants; and some particulars relating to Falkland's Islands", publicada em Hereford, Inglaterra, em 1774. O responsável pela publicação, elaborada a partir dos manuscritos do sacerdote, foi

\footnotetext{
${ }^{1}$ Falkner [1774], 2003: 115. Para conduzir este trabalho utilizamos especialmente duas edições do texto de Falkner. A mais antiga data de 1974, e a mais recente de 2003. São elas: Falkner, P. Tomas. Descripción de la Patagonia y de las partes contiguas de la America del Sur. Traducción y notas de Samuel A. Lafone Quevedo. Estudio Preliminar de Salvador Canals Frau. Buenos Aires: Librería Hachete, 1974, 174 pp. Esta obra fez parte da "Colección 'El pasado argentino' ”, dirigida por Gregorio Weinberg, sendo seu texto tomado de edição anterior (1910) publicada pela Universidad Nacional de la Plata, e também baseada na tradução feita por Lafone Quevedo. A outra edição que utilizamos foi organizada por Raúl José Mandrini que é, igualmente, autor do estudo preliminar que a acompanha: Falkner, Tomás. Descripción de la Patagonia y de las partes contiguas de la America del Sur. Buenos Aires, Taurus, 2003, 222 pp. Tanto a edição de 1974 quanto a de 2003 mantêm as notas de Lafone Quevedo. Uma advertência anterior ao início da obra esclarece que foi respeitada -o mais proximamente possível- a sua versão do texto, e que tão somente teriam sido feitos reparos na forma "especial de pontuação" do tradutor, isto para facilitar a compreensão por parte dos leitores. Além disto, nos valemos, também, de Furlong SI, Guillermo. Tomas Falkner y su "Acerca de los Patagones" (1788). Buenos Aires: Libreria del Plata, 1954, 216 pp.
} 
William Combe, escritor que gozava de relativa notoriedade na Inglaterra daquela época ${ }^{2}$.

Traduções do texto rapidamente circularam em alemão (1775) e francês (1785) ${ }^{3}$. Ele também foi prontamente vertido ao castelhano, embora, na Argentina, só viesse a ser publicado no século XIX como parte da Coleção de Pedro de Ângelis ${ }^{4}$. A partir destas considerações, buscamos desenvolver uma análise da singular fortuna desta obra, vinculando as condições de sua escrita à particular circunstância histórica em que Falkner se tornou um tradutor da realidade dos territórios austrais americanos aos seus interlocutores. Atentos às ponderações de Roger Chartier a respeito dos significados "móveis e plurais" dos textos, desenvolveremos também, uma reflexão sobre as vicissitudes de sua edição e recepção nos círculos leitores da época. ${ }^{5}$

\section{Um jesuíta inglês nas regiões austrais do Império Espanhol}

“... la relación de un viejo viajero” (William Combe, 1774)

Antes de se instalar em Hereford, onde, já idoso, escreveu sobre suas experiências na América do Sul, "Thomas Falkner” viveu uma vida aventurosa. Filho de um casal de calvinistas ingleses, ele nasceu em Manchester em 1702. Depois de iniciar seus estudos na cidade natal, transferiu-se para Londres ${ }^{6}$ a fim de cursar medicina. Ao término desta formação, empregou-se como médico e cirurgião da Compañía del Mar del Sur que recebera, pelo Tratado de Utrecht, o direito de comercializar escravos nas colônias espanholas do Novo Mundo. Destinado a participar de uma viagem para o Rio da Prata, foi comissionado em 1729 pela Royal Society de Londres como físico e botânico, incumbido de estudar as propriedades médicas das

${ }^{2} \mathrm{O}$ texto pode ser lido na sua primeira edição inglesa a partir da consulta ao site: https://archive.org/stream/descriptionofpat01falk\#page/n5/mode/2up. Acessado em 25 de julho de 2014.

${ }^{3}$ Mandrini, 2003:11.

${ }^{4}$ Pedro de Angelis, nascido em Nápoles em 29 de junho de 1784 e falecido em Buenos Aires em 10 de fevereiro de 1859, foi um dos primeiros "historiadores" da Argentina. Ele constituiu-se em um notável colecionista, que recopilou e publicou documentos inéditos sobre o passado do país que haviam permanecido inéditos até então. Uma edição de 2008 da Continente, da qual não nos valemos aqui, apresenta a "Descripción de la Patagonia" com o Discurso Preliminar de De Angelis

${ }^{5}$ A produção deste artigo é tributária da reflexões originadas na pesquisa referente ao projeto intitulado “Cruzar fronteiras, conectar mundos. O caso da pampa bonaerense no século XVIII”, que está sendo desenvolvido com o apoio do Conselho Nacional de Pesquisas - CNPq [Bolsa Produtividade]. Colaboram com o desenvolvimento da investigação os bolsistas de Iniciação Científica Henrique Cordeiro Hilgert (PROBIC-FAPERGS), Marcelo Augusto Silva (PIBIC -CNPq) e Ruth Lorenz (UNIBIC-UNISINOS). O projeto estuda as chamadas “missões autrais" -em que Tomas Falkner esteve diretamente envolvido-, como locus para analisar as questões de contato e intermediação cultural com os índios da pampa de Buenos Aires.

${ }^{6}$ Existem pequenas discrepâncias sobre aspectos até certo ponto secundários da vida de Falkner, por exemplo, relativamente a ele ter estudado em Londres ou na Universidade de San Andres de Edimburgo. Por isto mesmo, é necessário esclarecer que seguiremos neste trabalho as informações coligidas por Guillermo Furlong e que constam da obra “Tomas Falkner y sus 'Acerca de los Patagones' ” de 1954. Embora os trabalhos deste autor tenham uma forte marca institucional e clara intenção apologética, que cabem ao trabalho do historiador discernir, ele apresenta o melhor conjunto de dados que nos foi possível coligir. Certamente Furlong teve a sua disposição uma série de fontes que não eram acessíveis para outros interessados na vida deste personagem. Ver: Furlong, 1954. 
águas e ervas daquela região. Tais informações preliminares contribuem para delinearmos, embora ainda insuficientemente, a cena marcadamente dinâmica em que atuou o autor de que aqui nos ocupamos.

Com efeito, o final da Guerra de Sucessão Espanhola ocorrida nos primeiros anos do século XVIII (1700-1713), redundara em uma concessão para que os ingleses, por meio de um contrato de "asiento", comercializassem escravos africanos com os territórios ultramarinos castelhanos através do porto de Buenos Aires. Além disto, as diretrizes da nova dinastia no poder, os Bourbon, introduziriam, ao longo desta centúria, um conjunto de medidas que se destinavam a recuperar as combalidas finanças reais. As iniciativas conhecidas como "reformas bourbônicas" buscavam, entre outras coisas, tornar mais eficiente a relação com os territórios coloniais, de forma que estes fornecessem os meios para a desejada recuperação do reino. Medidas de fomento às economias regionais, valorização de seus produtos, e uma (relativa) liberalização do comércio, trarão importantes consequências para a região platina. Além disto, preconizou-se a necessidade de melhorias no aparato defensivo das colônias, tanto quanto de medidas de controle nas fronteiras com populações indígenas não submetidas. Quanto a estes territórios ainda não apropriados pela sociedade colonial, preconizava-se a necessidade de seu reconhecimento, de forma a garantir a sua posse e potencializar a exploração de possíveis riquezas. No caso do Atlântico Sul, a retomada da utilização do Cabo de Hornos para a navegação tornava ainda mais ingente esta necessidade.

A existência de grupos indígenas independentes nos extensos territórios que se estendiam de Buenos Aires para o sul inquietava as autoridades, temendo estas que os nativos pudessem entabular negociações prejudicias aos interesses de Sua Magestade com potências rivais ${ }^{7}$. Assim sendo, como veremos em outro momento deste artigo, o fato dos escritos de Falkner fornecerem conhecimentos tidos como estratégicos sobre a região e, de forma especial, a existência neles de certas passagens em que é apontada a fragilidade das defesas castelhanas, ecoaram negativamente nos círculos espanhóis.

Foi para um domínio ultramarino submetido a novas pressões e vicissitudes, portanto, que, aos 27 anos, Thomas Falkner embarcou na viagem que mudaria radicalmente os rumos de sua vida. Seu navio, provavelmente o Siria segundo informa Guillermo Furlong ${ }^{8}$, dirigiu-se inicialmente para a Guiné, onde recolheu a carga de escravos destinada para o porto de Buenos Aires, ao qual chegou em maio de 1730. Depois, acompanhando os africanos desembarcados, o médico partiu em direção ao interior, o que lhe oportunizou percorrer os territórios de uma ampla região. Falkner esteve então, em espaços não costumeiramente abertos à presença de estrangeiros, dirigindo-se para Santa Fé, Córdoba e Mendoza, e chegando finalmente, até Santiago do Chile, onde se encontrava em março de 1731. Desta cidade ele regressou para Buenos Aires onde, depois de recuperar-se de uma enfermidade, converteu-se ao catolicismo e ingressou na Companhia de Jesus.

Resulta ao menos institgante, relacionar a situação limite vivida pelo jovem calvinista, àquela que havia experimentado Inácio de Loyola na oportunidade em que viu despertar sua vocação religiosa. Não temos informação sobre o mal que acometeu o inglês, mas o certo é que, tendo sido atendido pelo $\mathrm{P}^{\mathrm{e}}$ Sebastián de San Martín da Ordem dos Jesuítas em sua convalescença, Falkner adotou o catolicismo e entrou, em

\footnotetext{
${ }^{7}$ Weber, 2007.

${ }^{8}$ Furlong, 1954: 14
}

51 Maria Cristina Bohn Martins Entre a escrita e a edição: “A Descrição da Patagônia” ... 47-66. 
1732, para a Companhia. Depois disto, dirigiu-se para Córdoba, principal sede dos jesuítas no Prata e onde se localizava o noviciado da Província, bem como a sua Universidade. Fez os votos em 1734 e, em 1739, concluídos seus estudos, sendo agora conhecido como "Tomás Falkoner", foi ordenado sacerdote. O religioso trabalhou como missionário fundando o povoado de Nuestra Señora del Pilar del Volcón (1747) na região interserrana que se localiza próxima da atual Mar del Plata. Passou temporadas na estância de Areco, lecionou em Córdoba e atuou como médico, entre outras coisas, até ser condenado ao desterro em 1767. Encaminhado à Cádiz e, depois, à Inglaterra, viveu aí até a sua morte em 1784, aos 77 anos de idade e 52 anos depois de conversão ao catolicismo, não sem antes escrever o material que serviu de base para a edição da “Descrição da Patagônia”.

\section{Textos do exílio: para uma memória da Companhia}

“... los jesuítas tenían claro que no solamente era menester trabajar por la 'defensa y dilatación de la fe católica' sino que también tenían que contarlo”. (Fernández Arrilaga, 2013)

Thomas Falkner fez parte de um grupo conhecido como a "geração dos exilados”, nomenclatura utilizada pela historiografia para fazer referência aos padres que foram desterrados pela Pragmática Sanção promulgada em 27 de fevereiro de 1767. Não se pode precisar o número exato dos envolvidos na traumática experiência desta expulsão, mas ele ultrapassou a cifra dos 2000 homens. ${ }^{9}$. Foram 449 os embarcados da Província Jesuítica do Paraguai à qual pertencia o autor de que tratamos aqui, compondo um grupo internacional muito ativo e dotado de grande preparação intelectual. Segundo Bartomeu Meliá, alguns dos sujeitos que foram obrigados a partir (entre os quais estavam Martin Dobrizhoffer ${ }^{10}$, José Sánchez-Labrador ${ }^{11}$ e José Manuel Peramás ${ }^{12}$ ), além de serem fontes indispensáveis para a etno-historia americana, podem

\footnotetext{
${ }^{9}$ Conforme Sainz Ollero, o total dos expatriados foi de 2276, dos quais 449 saíam do Rio da Prata (1989: 78). Já Carlos Page informa que uma relação datada de 3/06/1769 indica que chegaram ao Porto de Santa Maria 2116 sacerdotes, sendo 563 da Nova Espanha, 202 de Quito, 204 de Santa Fé, 406 do Peru, 302 do Chile e 449 do Paraguai (2011: 18). Uma vez na Europa, os jesuítas desterrados foram, na sua maioria, admitidos nos Estados Papais, muitos deles em Faenza, outros em Ravena, Brisighela, Bologna e Ímola. O inglês Thomas Falkner, depois de ter chegado a Cádiz, foi separado de seus colegas e enviado para a Inglaterra.

${ }^{10}$ Natural de Tubing, Áustria, Dobrizhoffer eio para o Novo Mundo em 1748. Assim como seu colega Florian Paucke, ele compunha o grupo que acompanhava o Procurador Ladislau Oroz naquele ano. Missionou entre os guaranis por 11 anos, e entre os abipones por 7. Expulso, fixou-se em Viena onde morreu em 1791. Antes disto, escreveu os 3 tomos da "História dos Abipones" publicada, em latim, no ano de 1784.

11 José Sanchez Labrador nasceu em La Guardia, Espanha, em 1717, ingressando na Companhia em 1731. Veio para a América em 1734 acompanhando a expedição do $\mathrm{P}^{\mathrm{e}}$. Antonio Machoni. Residiu em Córdoba, onde foi aluno de Filosofia na Universidade e, depois, professor da mesma. Foi ainda nesta cidade que ele se ordenou sacerdote no verão de 1739. Havia, portanto, 34 anos que estava no Novo Mundo quando foi desterrado. Erudito e prolífico, Sanchez Labrador produziu uma obra em mais de uma dúzia de tomos, os quais abarcam temas muito variados, que passam pela botânica e zoologia, pela linguística e etnografia, pela física e cosmografia, bem como por acontecimentos históricos que dizem respeito a esta região. Entre seus trabalhos destacam-se: El Paraguay Natural, El Paraguay Cultivado e El Paraguay Catolico, este último concluído no desterro

12 Nascido em Mataró, Barcelona, em 1732, Permás morreu logo depois da expulsão em Faenza, na Itália (1793). Seu labor missionário se desenvolveu centralmente no Paraguai, onde chegou em 1755 para
} 
ser considerados como precursores e fundamentais para as "novas ciências do homem”, como a linguística e a antropologia ${ }^{13}$.

No exílio, os homens desta "geração" escreveram obstinadamente, num exercício intelectual que deve analisado a partir de vários ângulos. Não resta dúvida que alguns destes textos podem ter respondido às necessidades pessoais dos autores, no sentido de ajudá-los a organizar suas recordações e emoções sobre o ocorrido ${ }^{14}$. Contudo, podemos concordar com a afirmativa de Inmaculada Fernández Arrillaga sobre o fato de que muitos deles são fruto de um trabalho meditado e reflexivo, apresentando uma intencionalidade manifesta. Por isto, "sus juicios son siempre críticos con sus enemigos y laudatorios para los jesuítas" ${ }^{15}$. Ou seja, buscando refletir sobre a construção de sentidos ${ }^{16}$ para esta "escrita do exílio”, podemos compreendê-la como forma de responder aos críticos da Ordem dando a versão dos próprios jesuítas sobre as atividades que lhes haviam gerado censura e suspeição.

É também conhecida a perspectiva segundo a qual os expulsos escreviam diante da nostalgia dos territórios e das obras às quais tinham dedicado, as vezes, largos anos de suas vidas. Há, também, quem encontre nos materiais formulados pelos religiosos uma forma de inserir-se na chamada "polêmica do Novo Mundo", debatendo com os detratores da natureza americana e dos povos do continente como Buffon, De Paw, Raynall e Robertson, entre outros. De acordo com Carlos Page, os jesuítas foram "los primeiros retractores de esas teorías" ${ }^{17}$. É em parte esta a interpretação emprestada por Beatriz Domingues para a Historia Antigua de Mexico de Francisco Javier Clavijero. De acordo com a autora, o exílio parece "ter fortalecido nos jesuítas mexicanos [...], e em Francisco Clavijero em particular, um vínculo com a pátria mexicana, que não foi somente afetivo, mas uma decisão intelectual”. Desta maneira, eles se propuseram a mostrar à Europa da Ilustração - na verdade pouquíssimo "ilustrada" no que se referia ao Novo Mundo, que conheciam basicamente através dos escritos dos filósofos ilustrados-, a real natureza e as histórias mexicana e americana" ${ }^{18}$.

Ainda de acordo com Domingues, devemos falar de "Ilustrações", de forma a retirar do movimento o aspecto de uma suposta unidade-uniformidade, reconhecendo as variantes que apresentou. Além das agendas de países que não a França e a Inglaterra, esta consideração sugere que os reinos ibéricos igualmente participaram do movimento cultural, sobretudo por meio de uma "Ilustração Católica” ou "Eclética", representada pelos jesuítas ${ }^{19}$.

concluir sus estudos. Foi um grande conhecedor da línguas guarani e lule, e escreveu uma obra bastante conhecida intitulada "Diario del Destierro".

${ }^{13}$ Meliá, 1988: 230.

${ }^{14}$ Bastante peculiar neste aspecto é a importante obra de Jose Chantre y Herrera que escreveu, sem jamais ter estado na América, uma "Historia de las misiones de la Compañía de Jesús en el Marañón español (1637-1767)”. No Prólogo do livro ele salienta que tomado de extrema melancolia, foi aconselhado por seus superiores a realizer a tarefa de compor um livro. Sem ter conhecido o Novo Mundo, escreveu apoiado em notícias e informações que recebia de companheiros que lá haviam missionado. Sobre o tema consultar: Girotto, 2013.

${ }^{15}$ Fernández Arrillaga, 2013: 71

${ }^{16}$ Chartier, 1990.

${ }^{17}$ Page, 2011: 54.

${ }^{18}$ Domingues, 2007:185.

${ }^{19}$ Ibíd.: 33. 
Segundo ela, escrevendo da Europa sobre a América, alguns jesuítas expulsos, especialmente os mexicanos, contribuíram para romper como regionalismo dos crioulos e para criar um sentido de auto-identificação. Se tais motivações, objetivos ou características são reconhecidas em mais de um autor, não podemos dizer o mesmo do responsável pela Descripción de la Patagonia. Para compreender esta assertiva, importa assim, acompanhar sua trajetória de produção e edição.

\section{“Papeles y notas” de jesuítas: uma descrição da Patagônia:}

"Convocado como modelo, o passado é naturalmente um passado constituído por fragmentos escolhidos" (Hartog , 2011)

O manuscrito que deu origem à “Descrição da Patagônia” é, em parte, resultado das observações elaboradas por Tomas Falkner ao longo dos quase quarenta anos em que ele viveu nos territórios castelhanos de ultramar. É razoavelmente consensuado contudo, que as autoridades encarregadas de providenciar o banimento dos religiosos impediram-nos de levar material escrito que não fossem seus livros de oração ${ }^{20}$.

Assim é que, narrando o trabalho de esboçar a figura de Cangapol, um importante cacique da região com quem conviveu, ele refere-se à necessidade de recuperar suas memórias: "He tratado de dibujar su retrato por lo que me acuedo de él” ${ }^{21}$. Para os interlocutores que o conheceram depois disto, era justamente esta experiência direta que valorizava a obra, haja vista que apresentava um conhecimento mediado pela vivência pessoal do autor sobre regiões distantes e ignotas. O próprio Falkner apela frequentemente no texto a esta condição de observador direto como meio de legitimar suas afirmações.

A obra, acompanhada de um mapa bastante criticado modernamente ${ }^{22}$, está composta em seis capítulos que são:

Capítulo I - Del suelo y productos de la parte más central de América;

Capítulo II - La descripcción del país de los índios, y de sus valles, serranias, ríos, etc.; El gran Río de la Plata, con sus afluentes, peces y puertos;

Capítulo III - Sigue la descripción del país de los índios, con sus vales, serranias, ríos, etc.; Tierra del Fuego e islas Malvinas ${ }^{23}$;

Capítulo IV - Description de los habitantes de la parte más austral de la América que figura en el mapa;

Capítulo V - Religión, gobierno, política y costumbres de los moluches y puelches;

\footnotetext{
${ }^{20}$ Guillermo Furlong sugere que o sacerdote inglês teria levado, não apenas seus manuscritos, como ainda alguns objetos: um traje dos índios patagões, uma taça elaborada de um "corno de boi" e uma vasilha feita de cobre chileno (1954: 94).

${ }^{21}$ Falkner, [1774] 2003: 88.

${ }^{22}$ Mandrini, 2003: 49.

${ }^{23}$ Uma já referida "Nota", postada ainda antes do "Estudio Preliminar" de Salvador Canals Frau para a edição da Hachete de 1974, assinala que, ao lado de "pequenos retoques" para a versão de Lafone Quevedo em que ela se baseia, o termo "Falkands" foi mudado para "Malvinas". Não resta dúvida que questões desta ordem referendam a necessidade de atenção às "lugares de produção" dos textos, de que fala Certeau (1988).
} 
Capítulo VI - De la lengua de los habitantes de esta tierra

Em vários momentos encontramos explícita esta posição de que quem narra é produtor de um conhecimento estabelecido sem mediação. Na introdução, Falkner afirma sobre seu mapa:

Algunas modificaciones he introducido yo en la costa oriental, que visite el año 1746, como también en la región del cabo San Antonio, donde estuve viviendo algunos años. En la descripción que hago del interior, por lo general me he ajustado a las próprias observaciones, porque lo he recorrido en gran parte (... $)^{24}$.

Posteriormente, na abertura do capítulo II, afirma sobre a região de Córdoba: "La primera vez que entré por aquellos lugares di con alguna gente de estos índios que aún se mantenía poblada en las márgenes de los ríos Segundo y Tercero” ${ }^{25}$. Mais adiante, assinala que nas margens do rio Carcarañá, havia farta quantidade de ossos grandes que lhe pareciam humanos: "He visto fémures, costillas (...) y en especial algunos molares que alcanzaban a três pulgadas de diâmetro en la base. (...). Yo en persona descubri la coraza de un animal que constaba de unos huesencillos hexágonos, cada un de ellos del diâmetro de una pulgada cuando menos (...)”26.

São recorrentes, com efeito, as passagens em que a experiência sensível e concreta aparecem descritas como fonte do conhecimento auferido. Ela surge como a norma que autoriza a produção do discurso. Assim como quando explica ter ele próprio provado as qualidades terapêuticas de certa planta ${ }^{27}$, o jesuíta também usa o argumento da "autópsia" 28 para narrar a descoberta e estudo de um animal que é tido hoje como o primeiro "achado" palenteológico argentino. Como vimos acima, ele diz, "Yo en persona" descobri a couraça de um animal. E ainda que, ao fazer um "examen anatómico de los huesos me convencí, casi fora de toda duda, que esto incremento inusitado no procedía de la acreción de matérias extrañas porque encontre que las fibras óseas aumentaban en tamaño en la misma proporción de los huesos”29.

Falkner portanto, não apenas oblitera o fato de que sua experiência não é relativa a todos os espaços narrados como, via de regra, não considera a dimensão temporal que o separava, enquanto produtor do texto, do sujeito que vivera aquilo sobre o que fala. Ou seja, que não nos é dado captar o tempo como ele ocorreu; por olharmos sempre a partir do presente, é preciso "reconstituí-lo" 30 .

Além disto, é bastante perceptível seu esforço em anotar o proveito possível dos dados que observa na geografia e na natureza, quase que os transformando em "produtos". Ao apontar e descrever árvores, ele explica o uso que lhe emprestavam os índios, bem como aquele que poderiam ter, em geral, para produzir remédios, gomas, incensos, para curtir couros, para utilizarem-se suas madeiras, etc. Sobre o salitre, diz:

\footnotetext{
${ }^{24}$ Mandrini, 1974: 53.

${ }^{25}$ Falkner, [1774] 1974: 75

${ }^{26}$ Ibíd: 82-83.

27 “Como yo y varios de mis amigos recogimos bastante bolsas de este té, y lo repartimos entre muchas personas, tuve ocasión de observar sus efectos, y de ello me resultó que dava apetito y que ayudaba a la digestión, siendo remedio contra jaquecas, apepsias crónicas (...) que se habían resistido a todos los demás remedios (...)”. Falkner, [1774] 1974: 73.

${ }^{28}$ Hartog, 2011.

${ }^{29}$ Falkner, [1774] 1974: 83.

${ }^{30}$ Hartog, 2011.
}

55 Maria Cristina Bohn Martins Entre a escrita e a edição: “A Descrição da Patagônia” ... 47-66. 
"podrá recogerse en grandes cantidades si se estableciese una industria” ${ }^{31}$. Embora não seja o caso de alongar as descrições deste tipo feitas pelo autor, é importante assinalar que ele parece estar bastante sintonizado com a perspectiva que animava a mirada dos reformadores ilustrados espanhóis no sentido de prospectar possibilidades econômicas para os territórios que se iam explorando.

Por outro lado, e de forma singular no corpo do que chamamos de "escrita jesuítica”, a narrativa de Falkner (que se vale frequentemente dos termos "útil” e "utilidade") não abre espaço para rememorações de ações apostólicas, suas ou da Ordem de que participa. Ela não guarda semelhança, desta maneira, com boa parte do alentado corpus elaborado pelos membros da Companhia de Jesus a partir de sua trajetória americana, em que encontramos as marcas da exaltação e defesa da ordem e do trabalho de seus agentes ${ }^{32}$. Esta situação é atribuída por Guillermo Furlong ${ }^{33}$ ao processo de edição sofrido pelo texto, matéria que analisaremos adiante.

Antes disto contudo, é necessário elucidarmos um outro ponto. Dissemos anteriormente que o manuscrito de Tomas Falkner em parte se constrói com base no que o jesuíta coligira pessoalmente em territórios que percorreu em sua estada no Novo Mundo. Entretanto, é sabido que diversas regiões apresentadas na "Descripción”, não foram diretamente conhecidas pelo jesuíta. Isto é, uma parte de suas "descrições" provêm de dados obtidos por outros caminhos que não a observação direta do autor. Assim sendo, embora o próprio título da obra se refira à "Patagônia", na verdade o seu autor não frequentou esta região.

Tras sua primeira viaje hasta Santiago de Chile, y tras su retorno a Buenos Aires, Falkner residió varios años en Córdoba durante su formación sacerdotal y los primeiros años de su vida religiosa. Fue entonces cuando visito Santiago del Estero, seguramente em mayo de 1742. En Córdoba volvió a residir nuevamente luego de su experiência por el sur bonaerense, actuando como sacerdote y médico, sin abandonar sus interesses como naturalista. Debió entonces conocer bien los alrededores de esta ciudad $\mathrm{y}$, sin duda, incursionó en las pampas cordobesas, donde debió tener sus primeros contactos con las poblaciones indígenas de las llanuras meridionales. También vivió en la desembocadura del río Carcarañá, en la actual província de Santa Fe -región que llegó a conocer bien-, entre 1752 y 1757 (...) como administrador de la estancia que poseía el Colegio de Santa Fe. Es probable que también visitara el delta del Parana, donde existía otra estancia jesuítica. No parece en cambio haber estado en los territórios del Chaco, ni en las misiones del Paraguay, como a veces se ha dicho" ${ }^{34}$.

Sua experiência mais importante todavia, ele obteve ao trabalhar como missionário nas reduções do sul bonaerense, mais especificamente na missão de Nuestra Señora del Pilar del Volcón, fundada por ele e José Cardiel em 1747. Desde este povoado ele percorreu os territórios adjacentes, na direção do litoral e do interior, estando aí em contato com distintas parcialidades indígenas, especialmente com aquelas que os documentos da época qualificam de "pampas e serranos", "patagones" das

\footnotetext{
${ }^{31}$ Ibíd.: p.65.

32 Sobre este tema ver: Oliveira, 2011, Martins, 2012c.

${ }^{33}$ Furlong, 1974.

${ }^{34}$ Mandrini, 2003: 23-24.
} 
distantes terras do sul, e “aucas", termo que dizia respeito aos índios transcordilheiranos ${ }^{35}$.

No seu trabalho como missionário, o "Padre Falkoner" conheceu bastante bem alguns personagens que foram protagonistas importantes do processo histórico em curso na região. Este é o caso do famoso cacique Cangapol, o Bravo, a quem já aludimos, cujas tolderias ficavam na região do Rio Negro, próximas do ponto de encontro entre o Limay e o Neuquén. Bravo foi um dos responsáveis por um poderoso ataque às propriedades hispano-crioulas em 1740, bem como foi um dos negociadores da instalação de missões na campanha de Buenos Aires. Esteve depois, também, envolvido nas ofensivas que culminaram na destruição e abandono de dois dos povoados missioneiros ali erigidos.

Falkner não apenas descreve o afamado líder indígena, como, tal qual registramos em outro momento, elabora um desenho dele:

He tratado de dibujar su retrato por lo que me acuerdo de él. Su persona y su traje están representados en el mapa, como también el de su mujer Huenec. Este caudillo llamado el cacique Bravo por los españoles, era alto y bien proporcionado. Debió medir unos siete pies y pulgadas de alto, porque parado yo en puntas de pies no podia alcanzar a la corona de la cabeza. Lo traté mucho e intimamente e hice algunas viajes con él. No me acuerdo haver visto índio alguno que aventajasse Cangapol en más de una o dos pulgadas de alto, y Sausimian, su hermano, no pasaba de los seis pies de alto ${ }^{36}$.

A seguir, ele aproveita para desqualificar as notícias cujas origens se encontravam no relato de Pigaffeta ${ }^{37}$, desmentindo histórias infundadas sobre os habitantes da Patagônia: "Los patagones o Puelches son gente corpulenta; mas nunca tuve noticias de esta nación de gigantes tan mentada por otros (...)”. Sobre a geografia da área, ele pretendeu assinalar a dificuldade dos estudiosos em estabelecer a sua longitude e, ainda, buscou corrigir versões distorcidas sobre sua extensão ${ }^{38}$.

O tema da "etnografia” produzida por Falkner é bastante polêmico, e suas informações foram amplamente desmerecidas neste aspecto, notadamente as "classificações" que ele produz. Tanto ele, quanto seus colegas Sanchez-Labrador e José Cardiel, foram profusamente utilizados e discutidos pela etnologia argentina tradicional de meados do século XX, especialmente no que tange ao esforço de definir "etiquetas étnicas” para as populações nativas. Os missionários, com efeito, se esforçam por apresentar um quadro em que procuram ordenar e classificar uma realidade altamente dinâmica, segundo critérios variáveis e recusados atualmente ${ }^{39}$. Apesar do [mau] uso que se fez destes "rótulos" todavia, Raúl Mandrini avalia que não se pode desconsiderar que Falkner brinda seus leitores com um primeiro olhar integral e

\footnotetext{
35 Ibíd.: 24.

${ }^{36}$ Furlong, 1974: 53.

37 Antonio Pigaffeta acompanhou a viagem de Fernão de Magalhães, mantendo um registro escrito da mesma. Neste "Diário" ele se refere à estatura desmesurada dos índios do extremo sul do continente: os "patagões".

${ }^{38}$ Furlong, 1974: 54-55.

39 Árias, 2009.
} 
compreensivo do mundo indígena da área, constituindo-se em testemunho fundamental sobre ele ${ }^{40}$.

Esta conclusão não implica em desconhecer os problemas da mirada que o jesuíta oferece sobre os grupos indígenas. Primeiramente, há que se ter em conta o "reducionismo" contido na sua observação ${ }^{41}$, isto é: um olhar que se dirige para populações a serem "civilizadas e convertidas". Também Fabian Árias, ao analisar as classificações étnicas que Falkner reproduz, discute a inconveniência de refletirem-se as informações do jesuíta como dados 'positivos', sem avaliar adequadamente a posição do mesmo "como observador y como cronista al mismo tiempo" ${ }^{42}$.

Até que ponto, questiona ele, podemos aceitar as descrições que encontramos nos textos dos jesuítas sobre as populações indígenas?

Por un lado, en una lectura macrohistórica los textos Jesuitas [...] se insertan en una tradición descriptiva que, a grosso modo, se puede definir como occidental, en tanto es desarrollada básicamente por europeos, pero que fundamentalmente se concentra en describir los hechos históricos en que los europeos se ven involucrados en detrimento de los 'otros' (Wolf, 1990). Por otro lado, los escritos referidos brindan una lectura regional (y hasta microhistórica en algunos casos concretos) que dan cuenta de los fuertes particularismos socio-históricos en los que incluso el narrador se ve claramente influenciado (y hasta diría capturado), mostrándonos una dimensión de la problemática general de la ‘conversión y aculturación’ mucho más fragmentada de lo que se imaginaron originalmente los estudiosos ${ }^{43}$.

Efetivamente, utilizar como fonte os textos dos jesuítas requer ter em perspectiva os "campos discursivos" em tensão. Todavia, também o fato de eles apresentarem-se problemáticos para enfrentarmos o problema das "classificações étnicas”, não deve levar a desconsiderarmos sua importância, crucial -inclusive- para entendermos as circunstâncias históricas da região em meados do XVIII. Por conseguinte, como dissemos, em que pesem os erros de informação consignados, a limitação das fontes de informação e os marcos conceituais com que operava o autor, a Descripción de la Patagonia vem a ser uma "fonte inapreciável” de dados sobre muitos aspectos da vida indígena ${ }^{44}$.

De outra parte, escritos como este davam aos europeus o acesso a um corpo de conhecimento enciclopédico sobre partes pouco ou nada conhecidas do Novo Mundo. "Foi esta informativa literatura jesuítica que pioneiramente proveu a Europa com um conhecimento detalhado da América (...), reforçando o [seu] exotismo (...), um importante traço do pensamento ilustrado" 45 .

Falkner escreveu um texto resumindo as vivências de um sujeito que, tendo se convertido ao catolicismo e ingressado na Ordem dos Jesuítas, não deixou de ter as qualidades de naturalista e herborista que haviam-no feito ser designado pela Royal

\footnotetext{
${ }^{40}$ Mandrini, 2003: 44.

${ }^{41}$ Meliá, 1988.

${ }^{42}$ Árias, 2009: 226.

${ }^{43}$ Ibíd.: 226

${ }^{44}$ Mandrini, 2003: 49-50.

${ }^{45}$ Domingues, 2007: 193.
} 
Society para partir em direção ao Novo Mundo nos finais do ano de $1729^{46}$. Pode assim conceitualizar uma apreciação sobre a realidade da região que chamou [sem exatidão para os dias de hoje] Patagônia, a partir de um campo que não é exatamente o da Igreja, mas sim daquilo que ia se constituindo como "ciência natural”.

Se atentarmos para alguns dos interlocutores citados por ele na obra, como é o caso do explorador francês Louis Antoine Bougainville, podemos supor que, ao menos no momento de escrevê-la, Falkner estava a par dos avanços das expedições que se organizavam "em nome da ciência”. Ele faz referência, também, à tradução inglesa da Viaje de Ulloa en la América del Sul, indicando que acompanhara os desdobramentos da Missão Geodésica Francesa de 1735 patrocinada pela Academia de Ciência da França e dirigida por Pierre Bouguier ${ }^{47}$.

O valor que assume o documento que produziu, nos ajuda assim a compreender que o jesuíta recebesse a visita de naturalistas afamados, ou que lhe fosse lhe fosse ofertada a edição de seus escritos, como veremos a seguir. Além disto, o material de Thomas Falkner portava informações que pragmaticamente interessavam a indivíduos como aquele que veio a ser o editor do manuscrito.

\section{De manuscrito a livro}

“ ... a questão essencial que, na minha opinião, deve ser colocada por qualquer história do livro, da edição e da leitura,b nn é a do processo pelo qual os diferentes atores envolvidos com a publicação dão sentido aos textos que transmitem, imprimem e lêem” (Chartier, 2006).

Em estudo preliminar ("Britanicos en el Rio de la Plata") à obra do seu colega jesuíta, Guillermo Furlong conta que Falkner foi visitado na Inglaterra pelo então celebrado naturalista Thomas Pennant, amigo e correspondente de Carl Liné e Buffon ${ }^{48}$. Na oportunidade, Falkner, ainda vigoroso aos 70 anos, "corporalmente activo, brusco en sus maneras como quiera que nunca llegó a abandonar las que adquirió en los treinta y ocho años que vivió entre los salvages”, teria compartilhado com Pennant parte dos seus conhecimentos sobre aquelas regiões distantes e exóticas ${ }^{49}$.

Percebe-se assim, que o jesuíta usufruiu de alguma notoriedade entre os círculos ilustrados da Inglaterra de sua época. Seus companheiros que se encontravam no exílio italiano e que, como dissemos, empenhavam-se em levar adiante aquilo que hoje pode ser tida com uma vasta "obra memorial” de sua missão americana, também tinham em boa conta a produção do colega inglês e, depois do falecimento deste, instavam para que se recuperassem seus “escritos y valiosos documentos”. Em relação a eles, "mencionan

\footnotetext{
${ }^{46}$ Ao apresentar dados biográficos de Falkner, Guillermo Furlong destaca que ele teria sido aluno de um afamado anatomista, Ricardo Mead, e do matemático e físico Isaac Newton (1974: 11). Esta experiência pregressa teria sido importante para que ele fosse o fundador da cátedra de Matemática da Universida de de Córdoba.

${ }^{47}$ Ele deve estar se referindo a Relación histórica del viaje hecho de orden de su Majestad a la América Meridional, publicada em Madrid, em 1748. Sobre a expedição e os textos que gerou, ver: Martins, 2012.

${ }^{48}$ Liné, botânico, zoólogo e médico sueco, foi criador da nomenclatura binomial e da classificação científica, e é considerado como o "pai da taxonomia moderna"; as teorias naturalistas do segundo, George-Loui Leclerc, conde de Buffon, influenciaram toda uma geração de estudiosos.

${ }^{49}$ Furlong, 1954: 93.
} 
entre otras cosas, una gran colección (4 tomos en folio) de observaciones botánicas, mineralógicas, etc., colecionadas por él en América. Ansian que en Inglaterra se publiquen estas obras" ${ }^{20}$.

Ainda segundo o biógrafo do jesuíta inglês, uma carta de 1788 indicava que seus colegas (os quais Furlong sugere que poderiam ser alguns de seus companheiros sulamericanos, todos eles personagens muito conhecidos entre os especialistas na área: Cardiel, Sanchez-Labrador, Camaño, Peramás, Muriel, Guevara, Jolis, e outros), almejavam obter estes materiais a fim de publicá-los:

Nuestros Padres hispano-americanos están muy contentos de saber que se han encontrado algunos fragmentos de los escritos de Falkner y esperan poder aprovecharlos. Los que le conocieran en Sur América, conservan (...) grande estima de sus conocimentos relativos a aquellos países. Esperan encontrar cosas tan útiles como curiosas en sus papeles, estén en la lengua que estuvieren ${ }^{51}$.

É possível ainda, que o inglês tenha escrito um extenso tratado sobre as enfermidades e suas curas por meio de drogas americanas, isto é, através de procedimentos que ele estudou em suas viagens pelas planícies de Santa Fé ou pela pampa bonaerense. Efetivamente, Falkner foi um médico respeitado e, segundo se diz, o único em Córdoba onde vivia no momento em que os jesuítas foram detidos e desterrados ${ }^{52}$. Este material contudo está perdido, e apenas se tem notícias a seu respeito a partir do que asseveram seus companheiros.

Desta maneira, sua única obra efetivamente publicada foi a "Descripción de la Patagonia y partes adjacentes ...”, não sem antes passar por um evidente processo de edição. Este processo iniciava-se pelo Proêmio, escrito por William Combe -que tivera a oportunidade de conhecer o manuscrito -, o qual introduzia o livro que veio a luz em Hereford, Inglaterra, em 1774.

Tal situação permite acompanharmos as reflexões de Ismael Calvi Silveira, baseando-se em Chartier, sobre as diferentes formas de "apropriação" de um escrito, especialmente em sua segunda acepção. $\mathrm{O}$ autor se refere ao:

[...] sentido de tomar posse, reclamar o poder sobre um texto para silenciá-lo; apropriação como entendimento, como atividade criativa que dá sentido(s) ao escrito, sentido(s) este(s) que pode(m) fugir do intuito original que o autor tinha quando escreveu; apropriação como forma de tornar a reclamar a propriedade do texto, defender a posse e tentar outorgar um sentido único e claro àquilo que foi escrito $^{53}$.

Além disto, há que se considerar não apenas que a figura do editor se torna crescentemente crucial ao processo de publicação ao longo do século XVIII, como ainda que, no caso que aqui importa, foi Combe que permitiu ao texto de um jesuíta proscrito alcançar o público leitor. A distante Patagônia chegava assim ao conhecimento do leitores da obra, a partir de um intrincado exercício de tradução que iniciava pelo

\footnotetext{
${ }^{50}$ Ibíd.: 97

${ }^{51}$ Ibíd.: 98.

${ }^{52}$ Em seu estudo preliminar, Furlong agrega interessantes notas (que teriam sido escritas pelo próprio Falkner) em que se descrevem procedimentos médicos que ele teria adotado no cuidado de alguns pacientes. Ibíd.: 75-80.

${ }^{53}$ Silveira, 2015: 92.
}

60 Maria Cristina Bohn Martins Entre a escrita e a edição: “A Descrição da Patagônia” ... 47-66. 
religioso que a observou, passava pelos informantes que o municiaram de notícias sobre o que não viu, bem como pelos interesses do editor que deu ao manuscrito a sua forma impressa.

Combe era um defensor da importância de angariar-se poderio marítimo e manuterem-se colônias no ultramar, ideias advogadas pelo primeiro ministro inglês William Pitt. É muito fácil conjecturar pois, que certas passagens do manuscrito de Falkner, como aquela que apresentamos na abertura deste texto, devem ter lhe parecido deveras interessantes. Em vários momentos elas vinham, efetivamente, ao encontro de juízos que ele esposava.

Ao conferir ao trabalho do jesuíta a sua forma impressa, o editor não deixou de se apropriar do seu conteúdo e de lhe conferir sentidos que não eram os mesmos do seu autor. Sobre isto é fundamental lembrar novamente Chartier, para quem nenhum texto "existe fora do suporte que lhe confere legibilidade; qualquer compreensão de um texto, não importa de que tipo, depende das formas com as quais ele chega até seu leitor [...]"54. De fato, embora afirme nas suas linhas iniciais que o material do religioso poderia servir de entretenimento a um público curioso, a sua leitura deixa bastante claros os objetivos do editor, os quais giravam em torno do que ele qualificou como “alguns interesses públicos”.

Assim sendo, uma vez que conhecera alguém que tinha vivido cerca de 40 anos na América do Sul e estudado a área, Combe, no Proêmio, conta ter obtido um mapa que seria resultado de observações pessoais do seu agente, bem como do que pudera ser averiguado através de outrem. A este material cartográfico, agregou-se uma descrição do "país" e de seus habitantes ${ }^{55}$.

Nas páginas em que apresenta a obra, o editor explicita seu apoio a uma política marítima ativa por parte da Inglaterra, assim como elenca os benefícios que julgava passíveis de resultar de uma participação mais intensa no comércio com as possessões da Coroa Espanhola. Ele ainda tece críticas ao que julga ser um pernicioso atrelamento sistema comercial imposto às colônias daquela, avaliando-o como "entorpecido" por "formalidades inúteis" e "demoras prejudiciais", que apenas serviam para favorecer práticas ilícitas $^{56}$. Deve ter, desta maneira, exultado com a apreciação de Falkner de que os colonos manifestavam descontentamento com a carestia das mercadorias e impostos exorbitantes ${ }^{57}$.

O editor advoga que a Inglaterra não tinha pretensões colonizadoras em relação aos territórios do império espanhol [não pretendendo despossuí-lo de nenhum território que lhe pertença], e afirma que suas posições nas Malvinas ${ }^{58}$ ou Gibraltar são

\footnotetext{
${ }^{54}$ Chartier, 1992: 220.

55 Respectivamente: "some public utility" e "becoming acquating with a person who had resided near forty years in South America, and had been enployed in surveing and making charts of the country, I obtained him the favour of him to make a map, according to what had himself observed, and what he had discovered from the relations of others; to which he added a description of the country, and of the Indian inhabitants”. Combe, In: Falkner, 1774: 01.

56 "This easily might be done without diminishing the public revenue of the King of Spain by altering the present complicated and uncertain mode of taxation and by abolishing unnecessary formalities, , tedious delays, and expensive aplications to the spain ministers [...]”. Ibíd.: 06-07.

${ }^{57}$ Falkner, [1774] 1974: 77.

${ }^{58} \mathrm{Um}$ estabelecimento nas Malvinas seria promissor: "The establishment of an english colony in Falklands Islands is said to be in consequence of an opinion ot the late Lord Anson, who thought that a
} 
meramente defensivas. Contudo, ele é pelo menos contraditório ao afirmar que não seria improvável que os navios ingleses, em algum momento, como amigos ou inimigos, tivessem que entrar pelo rio da Prata ${ }^{59}$.

Por isto mesmo, deviam ser de grande interesse para Combe passagens como aquelas em que a "Descrição" atesta o descontentamento dos hispano-americanos. Realmente, as informações de Tomas Falkner sugeriam que a Espanha teria grandes dificuldades em manter os territórios austrais, caso fosse atacada, o que, como sabemos, mostrou-se posteriormente um equívoco:

La gente de estes países no son gran cosa como soldados y tan descontentos se hallan con el gobierno español, mal estado de los negócios, carestia de todo lo que son mercaderías de ultramar, y lo que es peor, impuestos exorbitantes, etc, que de buen grado se verían subtidos de cualquier otra nación que los libertara de la opresión en quye se hallan sumidos. Y todo esto no obstante, el pais entero está sin mas defensa que una poca tropa veterana em Buenos Aires y Montevideo; y bastarría tomar a estas dos plazas para que todo el país se sometiera con sólo hacer un paseo militar por él, porque los criollos se harían unos con el enemigo, cuaquiera que fuese ${ }^{60}$.

O inglês não deixa de destacar que a principal razão para que levasse adiante o projeto editorial que apresentava, residia na sua expectativa de que pudesse haver uma "franca reconciliação" entre as cortes de Madrid e Londres, e que os comerciantes do seu país pudessem ter renovado o "trato de negros" a que haviam tido direito depois do Tratado de Utrecht. Segundo ele ainda, o comércio realizado por meio de Buenos Aires se apresentava muito mais vantajoso do que o que se podia realizar em Portobelo e Panamá, uma vez que ele podia colocar os negocianes em contato com as grandes províncias de Buenos Aires, Paraguai e Tucumán, além de Chile e Peru.

Combe, logo nos primeiros paragráfos de seu Prólogo destacou que o produto que ele apresentava ao público havia sido realizado a partir dos manuscritos do seu interlocutor. Não se tratava pois, do texto tal qual fora escrito pelo velho jesuíta. Embora assegure ter interferido apenas na linguagem e na ordem do material (não associando nada a ele), como já assinalamos, isto não representa pouca interferência: "Me permiti fazer algumas alterações na linguagem e na ordem do que foi escrito; mas não agreguei nada à relação do velho viajante"61.

Refletindo sobre os processos de mediação entre a autoria de um texto e o livro que resulta de sua publicação, Chartier avalia que, desde que eles adquiriram formas impressas com a invenção de Guttemberg, os impressores impõem suas marcas ao resultado final. Tais transformações determinam, muitas vezes, que todos aqueles implicados no processo de publicação tenham papel decisivo na "criação de sentido" do texto. Todos tornaram-se, de certo modo, autores dos livros diante de:

[...] uma pluralidade de intervenções implicadas na publicação dos textos. Os

settlement, and the fecuring a good harbour of a English ships, in the southern seas of America was a propor mesure for extending the commerce and marine empire of Great Britain”. Combe, 1774: 01.

59 "As it is probable that English ships may one day enter of the River Plate, either as friend or enemies [...]”. Ibíd.: 03.

${ }^{60}$ Falkner, [1774] 1974: 77.

61 "Some alteration has been made in the language and order of what he had wrote. But nothing has been added to the narrative of the old travel”. Combe, In: Falkner, 1778: 01. 
autores não escrevem livros, nem mesmo os próprios. Os livros manuscritos ou impressos, são sempre o resultado de múltiplas operações que supõe decisões, técnicas e competências muito diversas ${ }^{62}$.

Nesta perspectiva, os textos são uma construção feita a partir de vários materiais, que devem ser considerados para entendermos o modo como eles se erigem. As formas que dão a ler, a ouvir ou a ver os textos, participam, elas também, da construção de sua significação. Portanto, como aqui, os dispositivos que resultam da passagem à livro, ou a impressão do manuscrito do jesuíta, produzidos por decisão editorial ou pelo trabalho de oficina, podem não estar em conformidade com o pretendido pelo autor. Na falta do manuscrito original, não temos como avaliar mais exatamente as interferências que ele sofreu no processo que o transformou em um livro.

A mediação exercida por Combe pode ser uma explicação, por exemplo, para o fato de que a narrativa de Falkner não apresente aqueles traços que costumam ser apontados como distintivos de uma "escrita jesuítica", e que tinham norteado a tarefa escriturária de seus membros desde as orientações de Polanco, secretário de Loyola ${ }^{63}$. De fato, não há manifestações de pietismo e devoção, e nem as passagens de edificação que são bastante comuns entre os autores da Companhia. Também não se percebem indicações de defesa do labor jesuítico e debate com seus detratores.

Por outro lado, passagens como as que criticam a adminstração colonial espanhola, ou apontam a fragilidades de seu sistema defensivo, devem elucidar o fato de A Description of Patagonia não ter sido publicada na Espanha. Realmente, embora tenha sido traduzida ao castelhano por Manuel Machón, um espanhol residente na Inglaterra, que enviou o manuscrito para a corte madrilena, ela não foi publicada no reino e em suas possessões de ultramar, o que implicaria em uma as formas de “apropriação" - a primeira- a que nos referimos anteriormente. Na Argentina, como já informamos, foi Pedro de Angelis, quem a editou em sua Colección em meados do XIX.

Este dado ajuda, ainda, a pensar naquilo que os autores têm entendido como o "poder do leitor sobre o texto", e que implica nas formas pelas quais diferentes comunidades de leitores recebem um determinado escrito. Tendo em conta o peculiar momento histórico em que a obra foi dada a conhecer, marcado pelas profundas transformações na política internacional europeia, ela foi considerada como um desserviço à Espanha. De outro lado, foi tida como favorável aos interesses da Inglaterra que estava fortalecida pelas determinações do Tratado de Utrecht (1713) e ostentava a posição de ser, apoiada em sua armada, a grande controladora das rotas navais mais importantes. A nova dinastia no poder na Espanha por seu turno, orbitara para a esfera de influência francesa, o que marcava as posições em disputa.

É neste contexto que o livro de Falkner vem a luz, e algumas de suas passagens foram lidas com enorme interesse na Inglaterra e com forte temor na corte de Madrid, haja vista antecedentes como a viagem de George Anson aos mares do sul (1740-1741). Aquilo que foi compreendido como uma ameça em potencial na Espanha, estimulou expedições de exploração e reconhecimento dos territórios austrais, culminando com a fundação do Fuerte del Carmen em $1779^{64}$. Este movimento que então ganharia força,

\footnotetext{
${ }^{62}$ Chartier, 2010: 21.

${ }^{63}$ Oliveira, 2011, Martins, 2012

${ }^{64}$ Atual cidade de Carmen de Patagones
} 
dava continuidade a um processo de apropriação do território patagônico, o qual, em sua feição “intelectual”, tivera na “Descriptión” de Falkner um momento fundante.

\section{Referências}

Árias, Fabian (2009). "Las clasificaciones jesuitas del mundo indígena pampeano patagónico. El caso de Tomás Falkner, SJ, 1744-1774”. Revista sociedades de paisajes áridos y semiáridos. Universidad Nacional de Río Cuarto. Volumen 1, Año 1, pp. 225 - 243.

Assunção, José de Barros (2012). A fonte histórica e seu lugar de produção. Cad. Pesq. Cdhis, Uberlândia, v.25, n.2, pp. 407-429. Disponível em:http://www.seer.ufu.br/index.php/cdhis/article/view/15209/11834 Acessado em 15/12/2013.

Cañizares Esguerra, Jorge (2007). Como escribir la historia del Nuevo Mundo: Historiografias, epistemologias e identidades en el mundo del Atlántico del siglo XVIII. Mexico: Fondo de Cultura Económica.

Certeau, Michel de (1988). “A operação historiográfica”. In: A escrita da História, Rio de Janeiro: Forense Universitária, pp. 16-48.

Chartier, Roger (1992). “Textos, Impressos, Leituras”, In: Hunt, Lynn. A nova História Cultural. São Paulo: Martins Fontes, pp. 211-238.

(2002a). “A Mediação Editorial”, In: Chartier, Roger. Os Desafios da Escrita, São Paulo: Editora Unesp.

(2002b). Do Palco à Página: publicar teatro e ler romances na época moderna: séculos XVI-XVIII. Rio de Janeiro: Casa da Palavra.

---------- (2010). "Escutar os mortos com os olhos". Estud. av., São Paulo, v. 24, n. 69 , Disponível em http://www.scielo.br/scielo.php?script=sci_arttext\&pid=S0103 Acessado em 25 nov. 2014. http://dx.doi.org/10.1590/S0103-40142010000200002

Chiaramonte, José Carlos (2007). La ilustración en el Río de la Plata. Cultura eclesiástica y cultura laica durante el Virreinato. Buenos Aires: Sudamericana.

Domingues, Beatriz (2007). Tão longe, tão perto. A Ibero-América e a Europa ilustrada. Rio de Janeiro: Ed. Museu da República.

Falkner, Thomas (1784). A description of Patagonia, and the adjoining parts of South America: containing an account of the soil, produce, animals, vales, mountains, rivers, lakes, \&c. of those countries; the religion, government, policy, customs, dress, arms, and language of the Indian inhabitants; and some particulars relating to Falkland's Islands”. C Pugh: Hereford, 162p. Disponível em: https://archive.org/stream/descriptionofpat01falk\#page/n5/mode/2up. Acessado em 25 nov. 2014.

Falkner, P. Tomas (1974) Descripción de la Patagonia y de las partes contiguas de la America del Sur. Traducción y notas de Samuel A. Lafone Quevedo. Estudio Preliminar de Salvador Canals Frau. Prefacio de William Combe, Buenos Aires: Libreria Hachete. 
Falkner, Tomás (2003). Descripción de la Patagonia y de las partes contiguas de la America del Sur. Estudio Preliminar de Raúl José Mandrini. Prefacio de William Combe. Buenos Aires: Taurus.

(2008). Descripción de la Patagonia y de las partes contiguas de la America del Sur. Geografia, recurcursos, costumbres e Castro. Discurso preliminary por William Combe. Prefacio de William Combe, Buenos Aires: Continente.

Fernández Arrrilaga, Inmaculada (2013). Tiempo que pasa, verdade que huye. Crónicas inéditas de jesuítas expulsados por Carlos III (1767-1815). Alicante: Publicaciones de la Universidad de Alicante.

Furlong SI, Guillermo (1948), Naturalistas argentinos, durante la dominación hispânica. Buenos Aires: Huarpes.

(1954), Tomas Falkner y su “Acerca de los Patagones” (1788). Buenos Aires: Librería del Plata.

(1994), Los jesuitas y la cultura rioplatense. Prólogo de Fernado Storni, Buenos Aires: Biblos.

Gerbi, Antonello (1996). O Novo Mundo: História de uma polêmica (1750-1900). São Paulo: Companhia das Letras.

Girotto, Fernanda (2013). “A Amazônia do exílio: Os escritos de Chantre y Herrera”. Dissertação de Mestrado. Programa de Pós-Graduação em História da Unisinos. UNISINOS.

Hartog, François (2011). Evidência da História: o que os historiadores veem. Belo Horizonte: Autêntica Editora.

Mandrini, Raúl (2003). Estudio preliminar. In: Descripción de la Patagonia y de las partes contiguas de la America del Sur. Buenos Aires, Taurus, pp. 9-86.

Martins, Maria Cristina Bohn (2012a). "Uma jornada pela América Meridional e de volta à Europa: Charles Marie de La Condamine e o relato de sua expedição pelo Amazonas”. Estudos Ibero-Americanos, PUCRS, v. 38, n. 2, pp. 303-324.

(2012b). “História de histórias. Os jesuítas e as crônicas coloniais”. In: Karnal, Leandro; Domingues, Lourdes; Kalil, Luis G.; Fernandes, Luis E. de O. (Org.). Cronistas do Caribe, Campinas: Editora da UNICAMP, v. 12, pp. 71-92.

(2012c). "Índios e jesuítas em tempo de reduções: a historiografia e as missões austrais”. In: Fernandes, Luiz Estevam Oliveira. História da América: historiografia e interpretações, Ouro Preto: Ed. da UFOP, pp. 102-124.

Meliá, Bartomeu (1988). El guaraní conquistado y reducido. Ensayos de Etnohistoria, Asunción: CEADUC.

Oliveira, Paulo Rogério de Melo de (2011). “Um estilo jesuítico de escrita da história: notas sobre estilo e história na historiografia jesuítica”. Revista História e Historiografia, Ouro Preto, n. 7, nov/dez, pp. 266-278.

O’Neill Charles E.; Domingues, Joaquín M. (Org.) (2001). Diccionario Histórico de la Compañía de Jesús, Roma-Madrid: Institutum Historicum Societatis IesuUniversidad Pontificia Comillas. 
Page, Carlos A. (2007). Los viajes de Europa a Buenos Aires según las crónicas de los jesuitas de los siglos XVII y XVIII. Córdoba: Báez Ediciones.

(2011) Relatos desde el exílio. Memorias de los jesuítas expulsos de la antigua Provincia del Paraguay. Asunción: Servi Libro; Fundación Carolina; CSIC; CONICET.

Sainz Ollero, Hector el al (1989). José Sanchez Labrador y los naturalistas jesuítas del Río de la Plata. Madrid: Ministerio de Obras Públicas y Urbanismo.

SILVEIRA, Ismael Calvi (2015), Navegando em mares ilustrados: Ciência, política e discurso colonial na expedição Malaspina-Bustamante (1789-1794), Dissertação de Mestrado, Programa de Pós-Graduação em História, Universidade do Vale do Rio dos Sinos, Unisinos, 132 p.

Weber, David (2007). Los españoles y sus selvagens en la época de la Ilustración, Barcelona: Critica. 